\title{
ARTICLE
}

\section{Shielding Design of a Neutron Beam Line "NOBORU" at JSNS/J-PARC}

\author{
Masahide HARADA*, Kenichi OIKAWA, Yoshimi KASUGAI and Fujio MAEKAWA
}

Japan Atomic Energy Agency, Tokai-mura, Naka-gun, Ibaraki-ken 319-1195 Japan

\begin{abstract}
NOBORU, one of 23 instruments in the Materials and Life science experimental Facility (MLF) of Japan Proton Accelerator Research Complex (J-PARC), has been designed to evaluate characteristics of Japan Spallation Neutron Source (JSNS) and also used for a variety of applications. A heavy shielding structure was required for NOBORU to accept neutrons in very wide energy range up to $1 \mathrm{GeV}$ with a large neutron beam cross section of $10 \mathrm{x} 10 \mathrm{~cm}^{2}$ at $1 \mathrm{MW}$. Neutronics calculations were fully applied to examine the shielding structure. In the shielding calculation, we considered various loss points of the neutron beam caused by several experimental setups. As a result, a shielding structure satisfied the radiation dose limits adopted at J-PARC for all the loss point conditions. Effectiveness of the neutron beam shutter was evaluated for radiation safety point of view. In addition, we evaluated radioactivity of a $\mathrm{T}_{0}$ chopper, which needs a periodic hands-on maintenance, for the radiation safety. To confirm the shielding calculation, we have carried out preliminary dose rate measurements in the experimental room of NOBORU. The measured values were in good agreement with the calculated ones within a factor of 2.
\end{abstract}

KEYWORDS: J-PARC, JSNS, MLF NOBORU, shielding, neutron, dose rate

\section{Introduction}

Japan Spallation Neutron Source (JSNS) is a core equipment of the Materials and Life science experimental Facility (MLF) that is one of major experimental facilities in Japan Proton Accelerator Research Complex (J-PARC). The first neutron beam has been generated from JSNS on May 30, 2008. In the J-PARC project, a linear accelerator and a synchrotron are designed to provide a $1 \mathrm{MW}$ proton beam to a mercury $(\mathrm{Hg})$ target in JSNS. Three super-critical hydrogen $\left(\mathrm{H}_{2}\right)$ moderators $\left.{ }^{1-5}\right)$ at $20 \mathrm{~K}$ and $1.5 \mathrm{MPa}$ are located above and below the $\mathrm{Hg}$ target. They provide pulsed neutron beams to 23 neutron instruments for various neutron experiments.

NeutrOn Beam-line for Observation and Research Use $(\mathrm{NOBORU})^{6}$ is one of the instruments and is located at beam line 10 (BL10) aimed at a decoupled moderator. NOBORU has objectives to evaluate neutron source characteristics as well as to be served as a test beam port to promote various trial experiments. Concept and expected performance of NOBORU has been reported in Ref. 6) in detail. A sample position is $14 \mathrm{~m}$ away from the moderator. Neutron beam is transported in a vacuum duct. NOBORU furnishes a beam shutter, a couple of beam slits, a removable collimator, and so on. The beam line components in NOBORU cause neutron beam loss as samples do so. Therefore, shielding calculations for possible beam line configurations are needed.

The purposes of the present study are to secure appropriate level of the radiation safety by simulation study and to check reliability of the calculations by a preliminary experiment as the following. (1) We confirmed to satisfy a necessary radiation dose limits adopted at J-PARC by simulation calculations with consideration of every source conditions. The dose limit is $12.5 \mu \mathrm{Sv} / \mathrm{hr}$, a half of a

*Corresponding Author, E-mail:harada.masahide@jaea.go.jp

(C) Atomic Energy Society of Japan regulatory limit, for areas where experimenters can stay without time restriction. (2) Neutron dose rate at the sample position with the neutron beam shutter closed was also evaluated. The evaluation is important because an experimenter can access to the sample position when the shutter is closed. (3) We also evaluated residual radioactivity of the $T_{0}$ chopper because it is important in terms of radiation safety for maintenance work. (4) Finally, we measured neutron dose rates in the experimental room of NOBORU using pulsed neutron beam, and compared the measured results with calculation to confirm reliability of the calculation.

\section{Description of NOBORU}

Figure 1 shows three-dimensional cross-section view of NOBORU with JSNS. A sample position in the experimental room is $14 \mathrm{~m}$ away from the moderator. Neutron beam is transported in a vacuum duct with a cross-section of $10 \times 10$ $\mathrm{cm}^{2}$. NOBORU furnishes a beam shutter (made of $1.8 \mathrm{~m}$ steel and $0.2 \mathrm{~m}$ polyethylene) between $2.3 \mathrm{~m}$ and $4.3 \mathrm{~m}$ from the moderator, a couple of sintered $\mathrm{B}_{4} \mathrm{C}$ beam slits $(5 \mathrm{~mm}$ in thickness) at $7 \mathrm{~m}$ and $12.7 \mathrm{~m}$, a removable collimator (steel and polyethylene) at $12.5 \mathrm{~m}$, and so on. A remote controlled rotary collimator is installed at $7.5 \mathrm{~m}$ position in August, 2009. $\mathrm{A} \mathrm{T}_{0}$ chopper is planned to be installed at around $10 \mathrm{~m}$ position.

Outer size of the beam stop made of mainly steel, concrete and borax resin is $2.2 \mathrm{~m}$ in width, $2.4 \mathrm{~m}$ in height and $3 \mathrm{~m}$ in length. Used densities of the steel, concrete and borax resin are $7.5,2.2$ and $0.8 \mathrm{~g} / \mathrm{cm}^{3}$, respectively. Borax resin is a mixture of borax and polyethylene beads with almost equal weight fraction. Steel shields are effective to attenuate high energy neutrons while borax resin shields are for low energy neutrons.

The wall of the experimental room at the BL11 side is made of steel of $0.4 \mathrm{~m}$ in thickness and borax resin of $0.1 \mathrm{~m}$ in thickness. The opposite (BL09) side is made of double 


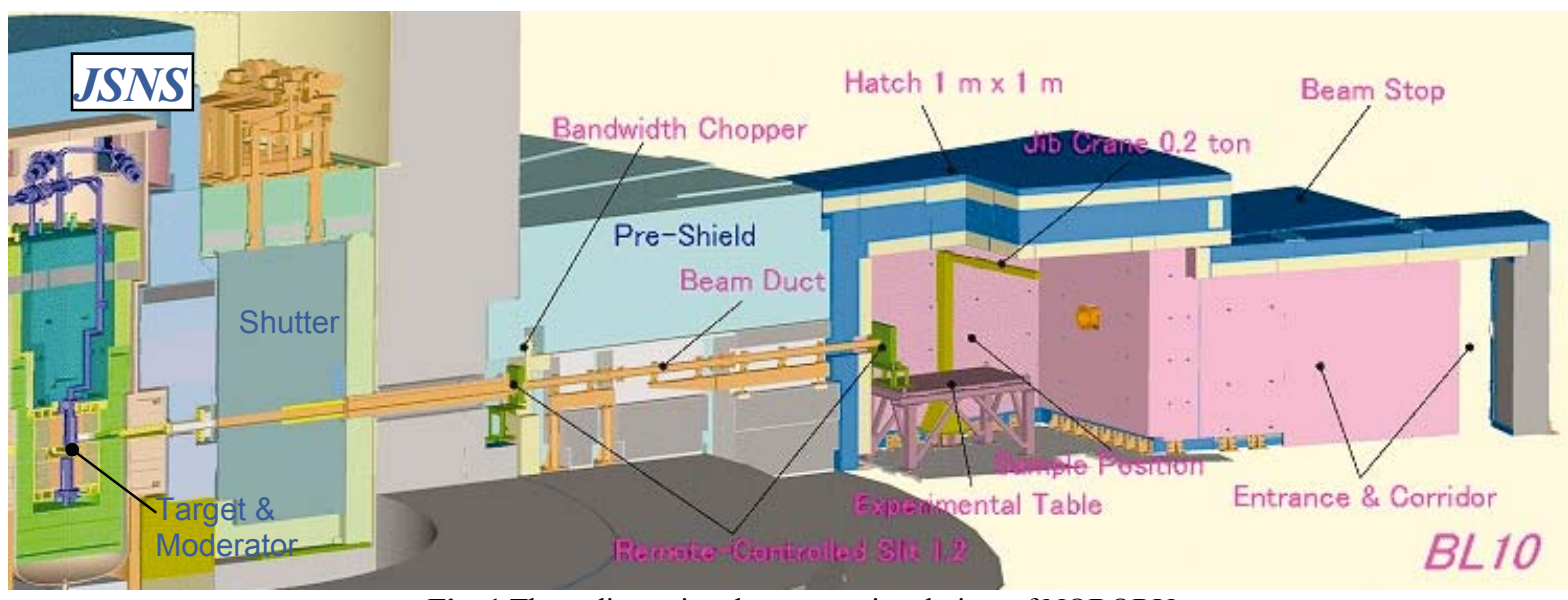

Fig. 1 Three dimensional cross sectional view of NOBORU

layers steel of $0.46 \mathrm{~m}$ in total thickness and those of borax resin of $0.3 \mathrm{~m}$ in total thickness. The ceiling wall consists of steel of total $0.56 \mathrm{~m}$ and borax region of total $0.4 \mathrm{~m}$ in thickness. The side walls are thinner than the ceiling to consider installations of neighboring beam lines of BL09 and BL11.

\section{Calculation methods and models \\ 1. Beam line shielding}

An evaluation method ${ }^{7,8)}$ for neutron beam line shielding was adopted in this study. The evaluation method is based on neutron current loss method $^{7)}$. An improved version of PHITS code ${ }^{8,9)}$ was used for the shielding calculation by which neutron and photon dose rates could be considered. The proton beam power was assumed to be $1 \mathrm{MW}$, that is, 3 $\mathrm{GeV}$ and $333 \mu \mathrm{A}$. Neutron flux data at the surface of the moderator for NOBORU in a whole energy region given in Ref. 10) and on a WEB site ${ }^{11)}$ were used as a source term.

Figure 2 shows a calculation model. Cubic steel with 10 $\mathrm{cm}$ was assumed as a sample because it gave the maximum beam loss condition. Case 1 and 2 represent models with and without the steel sample, respectively. The $\mathrm{T}_{0}$ chopper, the removable collimator and the rotary collimator were modeled in Case 3 through 5 as beam loss points.

\section{Dose rate at the sample position with the shutter closed}

The PHITS code and a simplified JSNS model were used. In this model, the core part of JSNS which was not related to

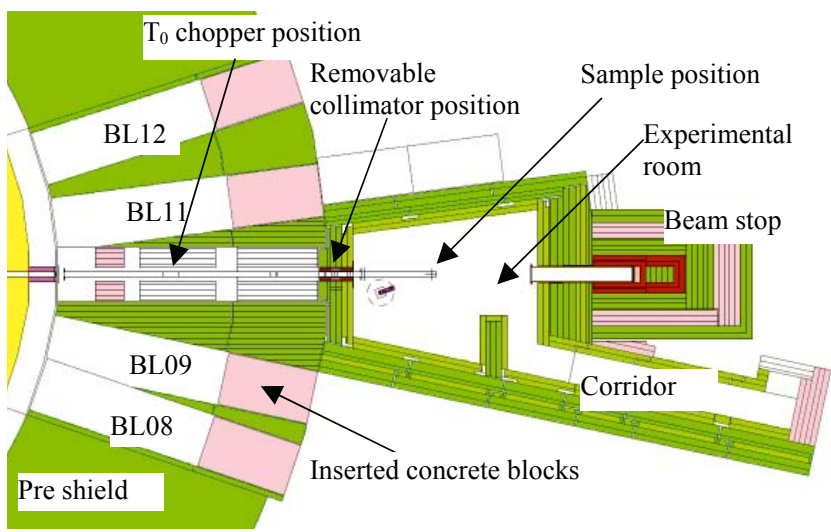

Fig. 2 Horizontal cutting view of the calculation model the calculation was simplified for the acceleration of the calculation. The calculation is initiated by injecting a proton beam to the mercury target. Dose rates at the sample position with the shutter opened and closed were evaluated. Effects of $0.2 \mathrm{~m}$ thick polyethylene behind the $1.8 \mathrm{~m}$ steel in the shutter block were investigated with replacing the polyethylene with the steel.

\section{Residual radioactivity of $\mathbf{T}_{\mathbf{0}}$ chopper}

The PHITS, DCHAIN-SP ${ }^{12)}$ and MCNPX ${ }^{13)}$ codes were used to evaluate residual radioactivity of a shielding block made of Inconel, called as "blade", of the $\mathrm{T}_{0}$ chopper. Neutron flux at the chopper blade was calculated by PHITS. Radioactivity of the chopper blade was calculated by DCHAIN-SP with the calculated neutron flux data. Finally, gamma-ray transport calculation was done with the MCNPX code with calculated gamma-ray source from DCHAIN-SP.

In this calculation, it was assumed that the chopper blade was made of Inconel X-750: major compositions were nickel $(73.08 \%)$, chromium $(15.50 \%)$, iron $(7.50 \%)$, and cobalt $(0.04 \%)$, niobium $(1.09 \%)$ and tantalum $(0.01 \%)$ were also considered as impurities. Operation condition was 30 years operation with the $1 \mathrm{MW}$ beam power and cooling time of 7 days after beam off.

\section{Calculation results \\ 1. Beam line shielding}

Figure 3 shows dose rate maps for the cases 1 and 2, that is, with and without the steel sample. The dose rate around the beam stop is below $10 \mu \mathrm{Sv} / \mathrm{hr}$. The dose rate at the door of the corridor is several $\mu \mathrm{Sv} / \mathrm{hr}$. Leakage neutrons are found around a junction between pre-shields and the experimental room wall because borax resin is lacking at this position. The dose rate at that part exceeds the dose limit value of 12.5 $\mu \mathrm{Sv} / \mathrm{hr}$. This is acceptable during operation with beam power much less than $1 \mathrm{MW}$ (about $250 \mathrm{~kW}$ ). The neighboring beam line at BL11 is to be constructed soon. After the construction, beam line shield for the BL11 attenuates the leakage neutrons properly, and the problem will be resolved.

Figure 4 shows dose rate maps in the cases from 3 to 6 . The case 6 exhibits maximum dose rate values among the cases 1 through 5 at each point. Dose rate distributions are 


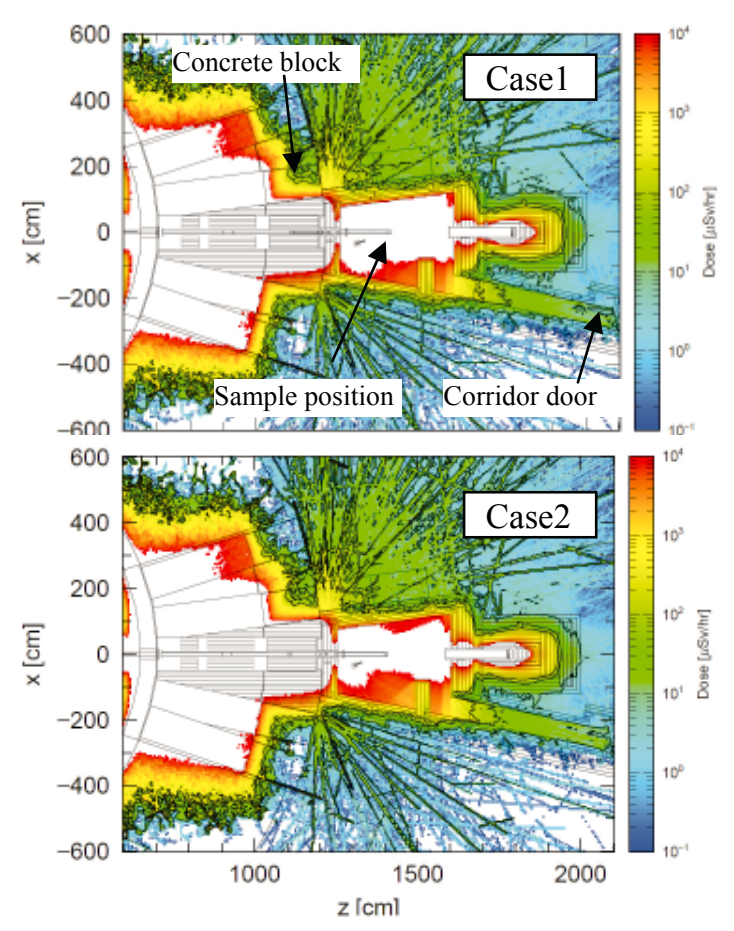

Fig. 3 Dose rate maps in case 1 and 2
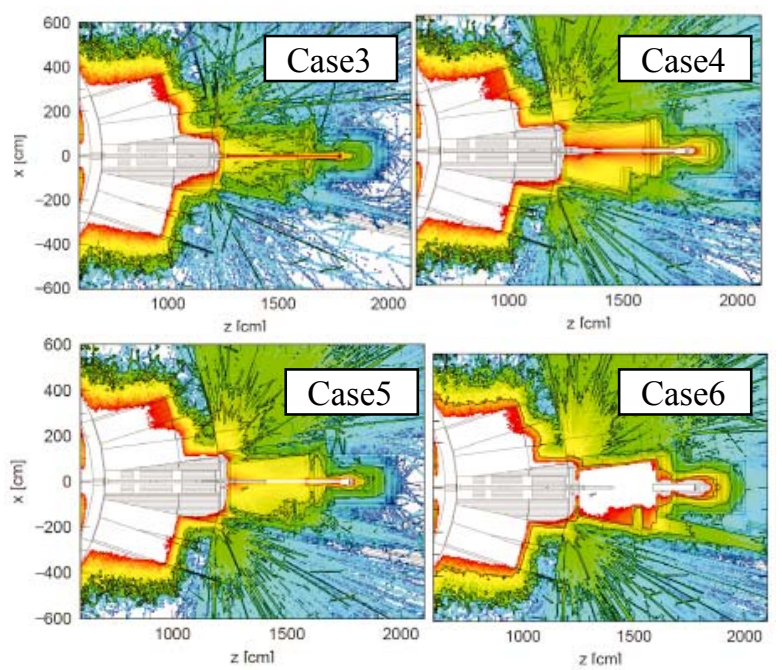

Fig. 4 Dose rate maps in the case from 3 to 6

different due to different beam loss points. It is found that concrete shield blocks of about $1.6 \mathrm{~m}$ in length filled in vacant beam lines are necessary to stop leakage neutrons from BL10 to the vacant beam line ports. No shielding performance is needed in the shielding door at the end of the corridor. Except for the junction point, dose rates outside the shield are less than the limit value of $12.5 \mu \mathrm{Sv} / \mathrm{hr}$.

\section{Dose rate at the sample position with shutter closed}

Figure 5 shows dose rate distributions along the beam line. Calculated dose rate at the sample position $(14 \mathrm{~m})$ is 7.5 $\mu \mathrm{Sh} / \mathrm{hr}$ when the polyethylene of $0.2 \mathrm{~m}$ in thickness is involved in the shutter block. The value is below the dose limit value. When the polyethylene is replaced with steel, the dose rate at the sample position increases about 400 times.

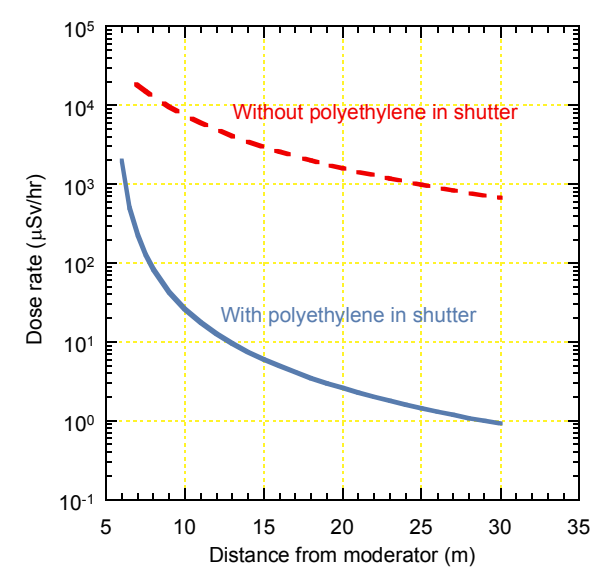

Fig. 5 Dose rates along the beam line. Two cases (with and without a polyethylene in shutter) are shown.

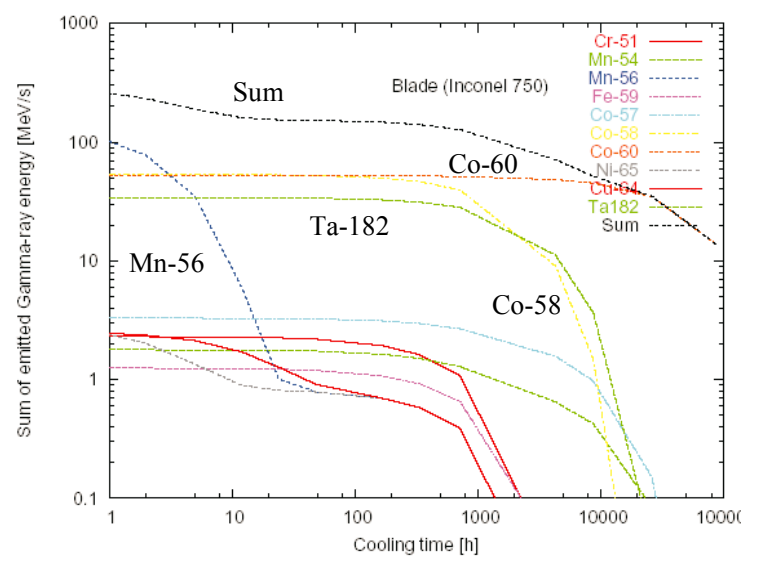

Fig. 6 Residual radioactivities of the $T_{0}$ chopper blade. These values are converted to the emitted gamma-ray energy.

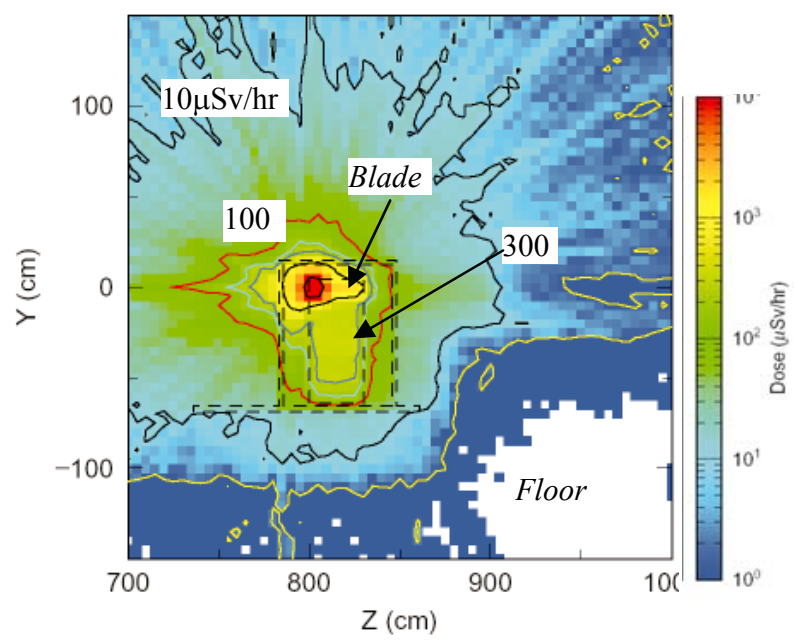

Fig. 7 Residual radioactivities of $\mathrm{T}_{0}$ chopper blade. These values are converted to the dose rate.

The reason is that neutrons in $\mathrm{keV}$ energy region penetrate in the steel shield and contribute significantly to the dose rate at the sample position. This result shows that polyethylene or any other hydrogen containing materials is inevitable in a steel shutter block to reduce considerably the dose rate at downstream of a beam line in MW spallation neutron sources like JSNS. 


\section{Residual radioactivity of $T_{0}$ chopper}

Figure 6 shows residual radioactivities of the chopper blade. At the cooling time of several hours, gamma-ray emission from Mn-56 (half life: $2.6 \mathrm{~h}$ ) is the largest. After 1 day cooling, Co-58 (half life: $71 \mathrm{~d}$ ), Co-60 (half life: $5.3 \mathrm{y}$ ) and Ta-182 (half life: $114 \mathrm{~d}$ ) contributes largely.

Figure 7 shows a dose rate map around the chopper blade at the cooling time of 7 days after beam off. The dose rates are about $300 \mu \mathrm{Sh} / \mathrm{hr}$ near the blade and about $10 \mu \mathrm{Sh} / \mathrm{hr}$ at $1 \mathrm{~m}$ from the blade.

\section{Preliminary measurement}

A Preliminary measurement of dose rate was performed in experimental room of NOBORU using a $10 \mathrm{~cm}$ cubic steel sample at the $14 \mathrm{~m}$ position. Incident proton beam power was $19 \mathrm{~kW}$. A remcounter "NS10001" manufactured by Fuji Electric Systems Co., Ltd. was used. Measured positions are depicted in Fig. 8.

Results of the measurements are summarized in Table 1 with comparing to the calculated values. The measured values are in good agreement with the calculated ones within a factor of 2 . This result indicates that the calculation method of the shielding design for NOBORU is reliable.

\section{Summary}

Shielding calculations for NOBORU with possible source term conditions were conducted. It was found that the shielding structure in the current design was sufficient for all the conditions to satisfy the radiation dose limit.

We evaluated effectiveness of the neutron beam shutter and radioactivity of the $\mathrm{T}_{0}$ chopper. The dose rate at the sample position of NOBORU when the neutron beam shutter is closed is $7.5 \mu \mathrm{Sh} / \mathrm{hr}$ that is below the dose limit. It was found that the $\mathrm{T}_{0}$ chopper blade made of Inconel was highly radioactive and some kind of protection tool would be required in the maintenance work.

To validate reliability of these calculations, we have performed preliminary measurement for dose rates in the experimental room of NOBORU during beam operation. The measured values were in good agreement with the calculated ones within a factor of 2 . In the future, when proton beam power will be increased (100 kw, at least), we will measure dose rates at outside of the shielding and at the sample position in the shutter closed case. And we will also measure background components in neutron scattering experiments.

\section{Acknowledgment}

The authors would like to acknowledge staffs of Center for Promotion of Computational Science and Engineering in JAEA for providing a parallel computer system, called PC Cluster for an exclusive use of the present calculations. The authors would like to thank Dr. M. Tamura in Hokuto Hospital at Obihiro-shi, Hokkai-do, Japan, for providing much helpful to construct the basic design of NOBORU. The authors would also like to thank Dr. K. Niita in Radiation Research Organization for Information Science \&

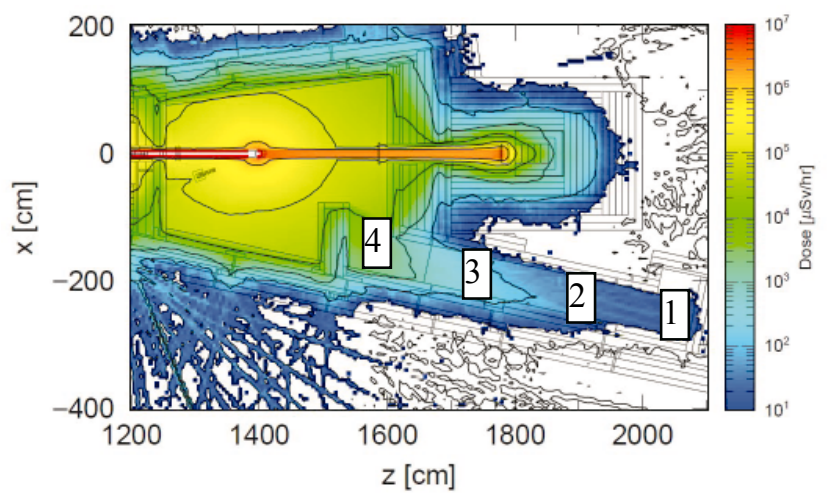

Fig. 8 Dose rate map at beam line height with positions of the measurements. Numbers in the map imply measurement positions

Table 1 Comparison of measured dose rates with calculated ones at each position depicted in Fig.8. These data are normalized to the case of $1 \mathrm{MW}$ proton beam power.

\begin{tabular}{|c|c|c|c|}
\hline $\begin{array}{c}\text { Position } \\
\text { Number }\end{array}$ & $\begin{array}{l}\text { Measurement } \\
(\mu \mathrm{Sv} / \mathrm{hr})\end{array}$ & $\begin{array}{l}\text { Calculation } \\
(\mu \mathrm{Sv} / \mathrm{hr})\end{array}$ & Cal./Exp. \\
\hline 1 & $3.3 \mathrm{E}+01$ & $1.7 \mathrm{E}+01$ & 0.5 \\
\hline 2 & $7.3 \mathrm{E}+01$ & $3.4 \mathrm{E}+01$ & 0.5 \\
\hline 3 & $3.7 \mathrm{E}+02$ & $2.1 \mathrm{E}+02$ & 0.6 \\
\hline 4 & $3.1 \mathrm{E}+03$ & $2.7 \mathrm{E}+03$ & 0.9 \\
\hline
\end{tabular}

Technology for providing much helpful data for this study.

\section{References}

1) N. Watanabe, M. Harada, T. Kai, et al., J. Neutron Res. 11, 13 (2003).

2) T. Kai, M. Harada, M. Teshigawara, et al., Nucl. Instr. Meth. A523, 398 (2004).

3) M. Harada, N. Watanabe, M. Teshigawara, et al., Nucl. Instr. Meth. A539, 345 (2005).

4) T. Kai, M. Harada, M. Teshigawara, et al., Nucl. Instr. Meth. A550, 329 (2005).

5) M. Harada, N. Watanabe, M. Teshigawara, et al., Nucl. Instr. Meth. A574, 407 (2007).

6) K. Oikawa, F. Maekawa, M. Harada. et al., Nucl. Instr. Meth. A589, 310 (2008).

7) F. Maekawa, M. Tamura, M. Kawai, et al., Proc. of 16th Meeting of the International Collaboration on Advanced Neutron Sources (ICANS-XVI), ESS 03-136-M3, 1247 (2003).

8) K. Niita, K. Suzuya, K. Nakajima, et al., Proc. ICANS-XVII, LA-UR-06-3904, 640 (2006).

9) H. Iwase and T. Nakamura, J. Nucl. Sci. Technol. 34, 1142 (2002).

10) M.Harada, N. Watanabe, M. Teshigawara, et al., Proc. ICANS-XVII, LA-UR-06-3904, 700 (2006).

11) Home page of Neutron Beam Performance of Material and Life Sciences Experimental Facility in J-PARC home page, http://j-parc.jp/MatLife/en/instrumentation/ns3.html

12) T. Kai, F. Maekawa, K. Kosako, et al., DCHAIN-SP 2001: High Energy Particle Induced Radioactivity Calculation Code, JAERI-Data/Code 2001-016, Japan Atomic Energy Research Institute (JAERI) (2001), [in Japanese].

13) D. B. Pelowitz, ed., MCNPX User's Manual, Version 2.6.0, LA-CP-07-1473, Los Alamos National Laboratory (LANL) (2008). 